\title{
LA REFORMA A LA JUSTICIA DEL TRABAJO
}

\author{
Alvaro Flores Monardes ${ }^{*}$
}

INTRODUCCION; I. Breve mirada a la actual Justicia del Trabajo; II. Los nuevos Juzgados del Trabajo y de Cobranza Laboral y Previsional (ley 20.022); III. Modificación a la ley 17.322 de Cobranza Previsional (Ley 20.023); IV. Los procedimientos Ordinario del Trabajo y de Tutela de Derechos Fundamentales (Proyecto de Ley en actual Tramitación): a. El nuevo procedimiento ordinario laboral; $b$. El Procedimiento de Tutela de Derechos fundamentales; $c$. Otros procedimientos y cumplimiento de la sentencia laboral; $\boldsymbol{V}$. A modo de conclusión: una evaluación de la Reforma a la Justicia Laboral.

\section{INTRODUCCION}

Las leyes 20.022 y 20.023 de mayo último, han significado puesta en marcha definitiva de la Reforma a la Justicia del Trabajo, en el marco del proceso de modernización de nuestro sistema judicial.

La primera ley crea los Juzgados Laborales y de Cobranza Laboral y Previsional y la segunda modifica principalmente la ley 17.322, relativa al procedimiento de cobranza de cotizaciones previsionales.

Se encuentra en actual tramitación ${ }^{1}$ el proyecto de ley que -entre otros aspectos- sustituye el Libro $\mathrm{V}$ del Código del Trabajo relativo al procedimiento ordinario laboral. El proyecto en tramitación introduce también un procedimiento de tutela de derechos fundamentales en el ámbito de la empresa y un procedimiento monitorio para acreencias laborales de cuantía menor.

El presente trabajo tiene como finalidad exponer los lineamientos principales de la reforma, no sin antes realizar un breve diagnóstico de la actual Justicia del Trabajo, para luego intentar identificar lo que se estima son las bondades y los defectos de la reforma, desde la particular visión de quien ha tenido la posibilidad de participar en ella desde su génesis como miembro del Foro para la Reforma a la Justicia Laboral en representación del Instituto de Estudios Judiciales y que ha sido además un operador del sistema -como suele denominarse desde cierto discurso a los jueces- primero, como relator de la Iltma. Corte de Santiago y en la actualidad, como Juez de la especialidad.

\footnotetext{
${ }^{*}$ Licenciado en Ciencias Jurídicas de la Facultad de Derecho de la Universidad de Chile. Juez del $8^{\circ}$ Juzgado del Trabajo de Santiago.

${ }^{1}$ En segundo trámite legislativo, en la Comisión de Trabajo del Senado.
} 


\section{Breve mirada a la actual Justicia del Trabajo}

Sobradamente sabido es que la Justicia del Trabajo ha sido objeto de una dramática postergación por casi ya tres décadas, situación que ha generado la profunda crisis que vive hoy este subsistema de justicia ${ }^{2}$.

Una simple mirada a ciertos datos numéricos ratifica lo señalado. Hacia 1971 (ley 17.574) existían en Chile 32 Juzgados del Trabajo. Suprimida la judicatura especial en 1981, la restauración de la misma, hacia el año 1986, restableció sólo 13 Juzgados en todo el país. Progresivamente el número aumentó, hasta llegar los 20 Juzgados actuales ${ }^{3}$, cifra claramente menor a aquélla que, al momento de crearse la judicatura especial -hace casi ocho décadas- contempló el legislador de acuerdo a las necesidades del país ${ }^{4}$.

Claramente el punto de inflexión de 1981 marcó el inicio de la crisis de la Justicia del Trabajo. La supresión de juzgados especiales de primera instancia, de las Cortes del Trabajo y en definitiva la desaparición de la especialidad, avenían claramente -por esos años- con el desmantelamiento, que a la par, sufría la normativa en sus aspectos protectores más significativos.

La desastrosa experiencia que significó la supresión de la justicia especializada, obligó a la administración castrense de la época a reponer los Juzgados del Trabajo (quedando, con todo, a firme, la eliminación de las Cortes especiales) resultando de ello, una justicia especial precarizada, en una muy desmedrada posición. En Santiago, por ejemplo, de diez juzgados suprimidos, se restauraron apenas cinco y sólo progresivamente se llegó a los nueve actuales; ello, sin considerar que la regresión iba a contramano del aumento progresivo de la población laboral y otros factores que, en el mediano y largo plazo, aumentarían la demanda por justicia del trabajo.

Otras cuestiones indispensables en el análisis, tales como la minusvaloración de la judicatura especial en la propia cultura institucional del Poder Judical ${ }^{5}$ y la falta de capacitación específica en el área, debieran abordarse en

\footnotetext{
2 Para un análisis más completo que el pretendido en estas líneas, véase Gazmuri Riveros, Consuelo; "La Justicia del Trabajo en Chile, realidad y perspectivas"; Cuaderno de Investigación N 21 de la Dirección del Trabajo; 2004 y Corvera, Diego; Análisis Crítico de la Justicia Laboral; Anuario de Derecho del Trabajo y Seguridad Social No 2, 2001 páginas 23 a 34.

39 en Santiago, 2 en San Miguel y los restantes 9 distribuidos en Iquique, Antofagasta, La Serena, Valparaíso, Rancagua, Concepción y Punta Arenas.

${ }^{4}$ El D.L. 207 de 1932 había establecido -en la génesis de la judicatura especial- 31 Juzgados en todo Chile.

${ }^{5}$ Suficientes ejemplos históricos de la Justicia del Trabajo como destino de miembros del Escalafón Primario sujetos de sanciones disciplinarias (traslado desde otros cargos de mayor "pedigree", aunque de la misma jerarquía) y la idea fuertemente asentada y refrendada por la práctica que la carrera judicial se ve estancada en esta judicatura, demuestran que en la cultura jurisdiccional, la judicatura del trabajo, tradicionalmente -de cuando en cuando- ha sido purgatorio y -casi siempre-
} 
un análisis más integral del tema, pero ello excede largamente los objetivos de este trabajo, bastando por ahora la referencia a los antecedentes cuantitativos que se han señalado, por estimárselos suficientemente ilustrativos de la pauperización de la Justicia del Trabajo que determina el escenario previo a la reforma.

\section{Los nuevos Juzgados del Trabajo y de Cobranza Laboral y Previsional (ley 20.022)}

La ley 20.022, siguiendo la lógica orgánica introducida por la Reforma Procesal Penal ${ }^{6}$ crea Juzgados de Cobranza Laboral y Previsional en Valparaíso, Concepción, San Miguel y Santiago. Un total de nueve jueces en cuatro tribunales ${ }^{7}$, que entrarán en funcionamiento el 1 de marzo de 2006 (artículo 16).

Se divide con ello la competencia laboral en dos tipos de tribunales especializados del Trabajo.

Se sustrae de los Juzgados de Letras del Trabajo las competencias de cobranza ejecutiva previsional, que representan aproximadamente el $82 \%$ de los juicios $^{8}$ y se entregan, junto al cumplimiento incidental de los fallos y los juicios ejecutivos originados en los otros títulos ejecutivos laborales, a los nuevos Juzgados especiales de Cobranza Laboral y Previsional.

Se crean también (siempre sobre la misma estructura de organización señalada) 40 Juzgados de Letras del Trabajo que inician su funcionamiento el 1 de marzo de 2007. Seis meses después se suprimen los actuales Juzgados del Letras del Trabajo, tras lo cual "las causas que se mantuvieren pendientes serán traspasadas a un Juzgado de Letras del Trabajo o de Cobranza Laboral y Previsonal según correspondiere" ( artículo $9^{\circ}$ transitorio).

El siguiente cuadro refleja el nuevo panorama creado por la reforma (se incluyen entre paréntesis los Juzgados actuales):

cementerio de la organización judicial. Con todo, el reciente nombramiento de Marta Maldonado, Juez del Trabajo de La Serena como Ministro de esa Corte pareciera marcar un cambio en la ley no escrita conforme a la cual desde esa judicatura no puede ascenderse a Ministro de Corte o cargo equivalente. Una golondrina no hace verano, puede pensarse todavía.

${ }^{6}$ Juzgados unipersonales de composición múltiple, en donde hay dos o más jueces y una administración separada de la función jurisdiccional entregada a funcionarios dependientes de un administrador, en todos los casos.

7 Tres Juzgados de Cobranza Laboral y Previsional con juez cada uno en Valparaíso, Concepción y San Miguel y un Juzgado, con seis jueces en Santiago (artículo $8^{\circ}$ )

${ }^{8}$ Gazmuri, Consuelo, op cit., p. 15; datos correspondientes a la ciudad de Santiago que concentra la mayor proporción de este tipo de juicios. 


\begin{tabular}{|c|c|c|}
\hline Ciudad & $\begin{array}{c}\text { Juzgado de Letras } \\
\text { del Trabajo }\end{array}$ & $\begin{array}{c}\text { Juzgados de } \\
\text { Cobranza }\end{array}$ \\
\hline Arica & 1 & - \\
\hline Iquique & $1(1)$ & - \\
\hline Antofagasta & $1(1)$ & - \\
\hline Copiapó & 1 & - \\
\hline La Serena & $2(1)$ & 1 \\
\hline Valparaíso & $2(2)$ & - \\
\hline Rancagua & $1(1)$ & - \\
\hline Curicó & 1 & - \\
\hline Talca & 1 & - \\
\hline Chillán & 1 & 1 \\
\hline Concepción & $3(2)$ & - \\
\hline Temuco & 2 & - \\
\hline Valdivia & 1 & - \\
\hline Puerto Montt & 1 & - \\
\hline Punta Arenas & $1(1)$ & 6 \\
\hline Santiago & $17(9)$ & 1 \\
\hline San Miguel & $2(2)$ & - \\
\hline San Bernardo & 1 & \\
\hline Total & & $\mathbf{4 0}(\mathbf{2 0})$ \\
\hline
\end{tabular}

\section{Modificación a la ley 17.322 de Cobranza Previsional (Ley 20.023)}

El procedimiento ejecutivo especial de cobranza previsional de la ley $17.322^{9}$ es modificado -en sus aspectos más relevantes- en lo siguiente:

a) Se otorga acción directa de cobro de cotizaciones previsionales al trabajador y a la organización sindical a que pertenezca, quienes podrán esgrimir como títulos ejecutivos las actas firmadas ante la Inspección del Trabajo que contengan un reconocimiento del débito previsional, la sentencia firme, la liquidación de remuneraciones en que conste la retención de las cotizaciones, junto al certificado de la institución previsional que establezca su no pago. Tal acción obliga la notificación de la acción a la institución de previsión respectiva, la que deberá continuar con en el procedimiento como demandante, en el plazo de treinta días de notificada, bajo apercibimiento de enterar con cargo a su patrimonio las cotizaciones adeudadas si no lo hace. Se contempla la misma

\footnotetext{
9 Del cual puede decirse que es una variante con defensas más limitadas del procedimiento ejecutivo común del Libro IV del Código de Procedimiento Civil y que contempla además la controvertida facultad de arresto respecto del deudor previsional moroso.
} 
sanción para otras hipótesis legales de negligencia en la actuación procesal de la institución previsional. ${ }^{10}$

b) Se modifican normas relativas a la ampliación de demanda sobre la base de nuevos títulos (las ampliaciones posteriores al primer requerimiento de pago, no hacen exigibles requerimientos posteriores).

c) Se crea una medida cautelar de retención de los dineros que correspondan por devolución de impuesto a la renta. A petición del ejecutante en la propia demanda, el tribunal deberá ordenar a la Tesorería General de la República imputar tales fondos a la deuda previsional.

La ley dispone también que en las comunas o agrupaciones de comunas en que no existan Juzgados de Cobranza Laboral y Previsional, las causa ejecutivas serán de competencia de los Juzgados de Letras del Trabajo y en las comunas en que no haya Juzgados de Letras del Trabajo, serán de competencia de los Juzgados de Letras con competencia en lo Civil (artículo 9ª).

\section{Los procedimientos Ordinario del Trabajo y de Tutela de Derechos Fundamentales (Proyecto de Ley en actual Tramitación)}

\section{a. El nuevo procedimiento ordinario laboral}

En segundo trámite legislativo se encuentra la reforma del procedimiento ordinario laboral que contempla la sustitución del procedimiento del Libro II, del título V del Código del Trabajo.

Los principios formativos del procedimiento están enunciados en el artículo 425 del proyecto: "Los procedimientos del trabajo serán orales, públicos y concentrados. Primarán en ellos los principios de la inmediación, impulso procesal de oficio, celeridad, buena fe, bilateralidad de la audiencia y gratuidad"

El diseño propuesto contempla la presentación de una demanda escrita, cuyos defectos formales deben ser advertidos por el Juez (quien ordena su corrección, bajo apercibimiento de tenerse por no presentada) la citación inmediata (primera providencia) a una única audiencia (que debe realizarse dentro de los cincuenta días siguientes a contar de la fecha de la resolución) en que se materializan los actos de conciliación y juicio.

Como trámite previo a la realización de la audiencia, se contempla el deber del demandado de presentar una minuta que contenga la base de sus alegaciones

\footnotetext{
${ }^{10}$ En los casos en que no entable la acción ejecutiva dejando transcurrir el plazo de prescripción, no solicite con la demanda la medida cautelar que la ley introduce y no interponga los recursos legales que establece la ley, si de ello se derivare perjuicio previsional directo.
} 
(la contestación oral posterior en la audiencia, no podrá contener más alegaciones que las contenidas en la minuta).

La audiencia comienza con el llamado a conciliación del Juez, quien propone las bases para un posible acuerdo, contemplándose la posibilidad de acuerdos parciales (lo conciliado se estima sentencia ejecutoriada para todos los efectos legales) que originan la ejecución inmediata de lo pactado.

En el caso de no llegarse a un avenimiento o de adoptarse sólo un acuerdo parcial ${ }^{11}$ se procede en el siguiente orden: ratificación de la demanda, contestación oral $^{12}$ (defensas formales y de fondo ${ }^{13}$ ), recepción de la causa a prueba (sin fijación de puntos de prueba), recepción de la prueba ${ }^{14}$, alegaciones orales de las partes sobre la prueba rendida y sentencia ${ }^{15}$.

La sentencia definitiva puede dictarse al término de la audiencia, con menos exigencias formales que las que impone aquella que haya de pronunciarse dentro de los siguientes quince días (si se opta por esta última alternativa, podrá también el Juez, al término de la audiencia, señalar las bases fundamentales del fallo).

La sentencia definitiva es recurrible sólo mediante recurso de nulidad ante la Corte de Apelaciones respectiva cuando hubiere sido dictada con infracción de garantías constitucionales o con infracción de ley que hubiere influido sustancialmente en lo dispositivo del fallo, y ante la Corte Suprema si respecto de la materia de derecho objeto del recurso existieren distintas interpretaciones sostenidas en diversos fallos emanados de tribunales superiores de justicia.

\footnotetext{
${ }^{11}$ En ausencia de controversia el Juez dicta sentencia al término de la audiencia o cita a las partes para una audiencia dentro de décimo quinto con el objeto de notificar la sentencia..

${ }^{12} \mathrm{La}$ reconvención, si la hubiere, ha debido deducirse en forma con la minuta previa a la audiencia y sólo debe ratificarse en la audiencia.

${ }^{13}$ El tribunal deberá pronunciarse de inmediato sobre las excepciones de incompetencia, falta de capacidad o de personería del demandante, de ineptitud del libelo, prescripción o aquella en que se reclame del procedimiento, siempre que aparezcan manifiestamente admisibles. Cuando fuere procedente, se suspenderá la audiencia por el plazo de cinco días a fin de que se subsanen los efectos u omisiones bajo el apercibimiento de "no continuarse adelante con el juicio".

${ }^{14}$ La prueba se caracteriza por la amplitud de medios admisibles, la proscripción de la prueba ilícita, la apreciación de acuerdo a las reglas de la sana crítica de los elementos de convicción, la inadmisibilidad de tachas de testigos, la interrogación directa (sin pliegos ni minutas) a absolventes y testigos por parte del tribunal y abogados, la resolución de objeciones e incidencias relativas a la misma en la audiencia y la existencia de facultades judiciales para reducir el número de testigos en casos calificados.

15 Como medida para mejor resolver, y sólo si se estima estrictamente necesaria para la acertada resolución de la causa, el Tribunal puede reiterar alguna diligencia que se encontrare pendiente solicitada por alguna de las partes.
} 
Otras causales de nulidad dicen relación con vicios relativos al Tribunal (incompetencia, implicancia, recusación), vulneración en la audiencia a los principios formativos del procedimiento (publicidad, continuidad del juicio y otros que tengan previsto legalmente la nulidad procesal como sanción) y vicios de la sentencia (ultra y extrapetita, decisiones contradictorias o pronunciamiento contra otra pasada en autoridad de cosa juzgada).

Otros institutos procesales generales que se introducen y que han de tenerse en cuenta para una comprensión cabal del nuevo procedimiento son:

a) Notificaciones por medios electrónicos (previa solicitud de parte).

b) Facultades cautelares amplias del Juez (v.gr. medidas precautorias de oficio).

c) Facultades del Juez para impedir el fraude la colusión, el abuso de derecho y las actuaciones dilatorias.

d) Registro del juicio oral en un acta resumida.

e) Nulidad insaneable en caso de infracción al mandato de desarrollo íntegro de la audiencia ante el juez de la causa.

f) Prohibición de suspensión de la audiencia una vez iniciada. Sólo excepcionalmente puede suspenderse mediante resolución fundada en caso fortuito o fuerza mayor.

\section{b. E1 Procedimiento de Tutela de Derechos fundamentales. ${ }^{16}$}

Se introduce también un procedimiento cautelar para las situaciones en que, con ocasión de la relación de trabajo, se vean afectados los derechos fundamentales de los trabajadores "entendiéndose por éstos los consagrados en la Constitución Política de la República en su artículo 19, números $1^{\circ}$ inciso primero, $4^{\circ}$ inciso primero, $5^{\circ}$ en lo relativo a la inviolabilidad de toda forma de comunicación privada, $6^{\circ}$ inciso primero, $12^{\circ}$ inciso primero y 16 en lo relativo a la libertad de trabajo, al derecho a su libre elección y a lo establecido en su inciso cuarto, cuando aquellos derechos resulten lesionados en el ejercicio de las facultades del empleador, aplicándose también el procedimiento para conocer de los actos discriminatorios a que se refiere el artículo $2^{\circ}$ del Código del Trabajo ${ }^{17}$.

\footnotetext{
16 Sobre Ciudadanía Laboral o Derechos Fundamentales en la Empresa, véase "Derechos Fundamentales. Homenaje al Profesor Patricio Novoa Fuenzalida". Anuario de Derecho del Trabajo y Seguridad Social; Sociedad de Derecho del Trabajo y de la Seguridad Social, No 3/2004; Lizama Portal, Luis y Ugarte Cataldo, José, Interpretación y Derechos Fundamentales en la Empresa, Editorial Jurídica Conosur ; 1998; Flores Monardes, Alvaro, "Algunas Notas sobre Derechos Fundamentales y Derecho del Trabajo"; en http//www.iej.cl; 2004.

17 "Los actos de discriminación son las distinciones, exclusiones o preferencias basadas en motivos de raza, color, sexo, edad, estado civil, sindicación, religión, opinión política, nacionalidad, ascendencia nacional u origen social, que tengan por objeto anular o alterar la igualdad de oportunidades, de trato en el empleo y la ocupación" (inciso cuarto del artículo $2^{\circ}$. Véase también inciso sexto y sexto relativos a actos de discriminación en ofertas de trabajo)
} 
Se confiere la acción a trabajadores, organizaciones sindicales ${ }^{18} \mathrm{y}$ se establece el deber de denunciar de la Inspección del Trabajo, cuando en el ejercicio de las facultades fiscalizadoras constate la vulneración de tales derechos (los hechos denunciados de que de cuenta el informe de fiscalización se introducen al procedimiento, revestidos de una presunción legal de veracidad).

El procedimiento es oral y goza de preferencia respecto de todas las demás causas. El Juez deberá requerir el informe de fiscalización de la Inspección del Trabajo respectiva y disponer la realización de una audiencia única dentro de los quince días siguientes a la fecha de la resolución, la que se realizará con el denunciante, el denunciado y los presuntamente afectados ${ }^{19}$.

La sentencia deberá dictarse en la misma audiencia o dentro de quinto día, deberá declarar la existencia o no de la lesión de derechos fundamentales; en caso afirmativo, ordenar su cese inmediato bajo apercibimiento de multa de 100 a 150 unidades tributarias mensuales (repetible), indicando concretamente las medidas a que se encuentra obligado el infractor, dirigidas a obtener la reparación de las consecuencias derivadas de la vulneración de derechos fundamentales, bajo el mismo apercibimiento, incluidas las indemnizaciones que procedieren.

Si la vulneración de los derechos fundamentales se hubiere producido con ocasión del despido, éste no producirá efecto alguno confiriendo al trabajador un derecho alternativo a la reincorporación, a saber: el de la indemnización por años de servicios con su recargo, más una indemnización adicional que fijará el Juez de la causa (no inferior a tres meses ni superior a once meses de la última remuneración mensual).

\section{c. Otros procedimientos y cumplimiento de la sentencia laboral}

El proyecto establece también un procedimiento monitorio para causas de mínima cuantía que se inicia con el reclamo ante la Inspección del Trabajo, la que, en la hipótesis de no haberse producido conciliación, remite al tribunal del Trabajo copia de lo obrado en el comparendo respectivo con los instrumentos acompañados por las partes, debiendo al Juez, sobre el mérito de lo obrado en la instancia administrativa, acoger o rechazar las pretensiones del reclamante si las estimare -en uno u otro caso- fundadas o infundadas, notificándose por carta certificada la resolución a las partes, quienes dispondrán de un plazo de cinco días para reclamar de la resolución dictada, recurso que dará origen a la realización de

\footnotetext{
${ }^{18}$ Que debe ajustarse a la forma de la demanda ordinaria, bajo sanción de no darse tramitación a las denuncias que no cumplan con sus requisitos.

${ }^{19}$ En la primera resolución, en lesiones de especial gravedad o cuando la vulneración denunciada pueda causar efectos irreversibles, el Juez de oficio o a petición de parte, podrá disponer la suspensión de los efectos del acto impugnado, bajo apercibimiento de multa de cien a ciento cincuenta unidades tributarias mensuales (repetible hasta obtener el debido cumplimiento).
} 
una audiencia (dentro de décimo quinto día) conforme a la forma dispuesta para el procedimiento ordinario.

Bajo un procedimiento similar al ordinario laboral (citación a una audiencia única) se substanciarán también las reclamaciones de multas administrativas.

El cumplimiento de la sentencia y el juicio ejecutivo de los demás títulos laborales se entrega a los Juzgados de Cobranza Laboral y Previsional. En el primer caso, ejecutoriada la sentencia (el recurso de nulidad -cabe anotar- suspende su cumplimiento) se da inicio de oficio a la ejecución.

\section{A modo de conclusión: una evaluación de la Reforma a la Justicia Laboral. $^{20}$}

Parece temprano para una evaluación de la Reforma en su diseño normativo, especialmente si se tiene en consideración que no ha cristalizado aún el proyecto más importante de todos, relativo a los procedimientos ordinarios y de tutela de derechos fundamentales.

Sin embargo, de manera preliminar pueden anticiparse algunos juicios en las cuestiones orgánico funcionales que no han de sufrir cambio alguno (normados por las leyes 20.022 y 20.023) y postularse otros -con la necesaria salvedad metodológica que se ha hecho al respecto- en cuestiones de procedimiento, que se advierten como esenciales en el proyecto en tramitación.

La reforma da un salto cualitativo en lo relativo al número de jueces que instituye, pero no tiene el alcance territorial de las reformas que la preceden.

Si bien implica un notorio aumento de jueces, parece haber sido pensada exclusivamente para Santiago (ciudad que concentra el aumento más significativo), soslayando la realidad de regiones relevantes por su importancia poblacional y fuerza laboral ${ }^{21}$.

\footnotetext{
20 Véase con más detalle: "Informe de los Jueces Laborales a La Reforma de la Jurisdicción del Trabajo", en Cuadernos Judiciales $N^{\circ} 8$, Instituto de Estudios Judiciales, mayo 2004 (informe sobre los Proyectos del Ejecutivo presentado por la Asociación Nacional de Magistrados a la Cámara de Diputados). Más recientemente también: "Observaciones de la Asociación Nacional de Magistrados al Proyecto de ley aprobado por la Cámara de Diputados que sustituye el procedimiento laboral del Libro V del Código del Trabajo", (inédito, entregado a la Comisión de Trabajo del Senado en julio último, contiene las observaciones al Proyecto aprobado por la Cámara de Diputados y en actual revisión del Senado; ).

${ }^{21}$ Para muestra un botón.: En Iquique ningún Juzgado de Cobranza se crea. No se aumenta el número de Jueces especializados. El solitario Juez de Iquique -instalada la reforma el 1 de marzo de 2007- deberá ser Juez Oral (asumiendo nuevas competencias no cuantificadas ni siquiera sospechadas en su impacto sobre el sistema, cual es el caso de las acciones de tutela de derechos fundamentales), deberá ser Juez de Cobranza, y, cuando por ley se elimine el antiguo Juzgado del
} 
Por otra parte, la reforma es un gran paso adelante en la tarea de dar tutela efectiva a los derechos laborales específicos e inespecíficos de los trabajadores ${ }^{22}$, tanto por el procedimiento ordinario que instituye, cuanto por el procedimiento específico de tutela de derechos fundamentales. En efecto, el procedimiento ordinario laboral propuesto aviene satisfactoriamente con los postulados esenciales del debido proceso ${ }^{23}$ e introduce un necesario arbitrio de amparo de los derechos fundamentales ante el Juez especializado (a partir de la constatación empírica del absoluto desuso del recurso de protección por la parte más débil de la contratación laboral) incorporando así a la esfera del control jurisdiccional un ámbito hasta ahora situado en los extramuros del derecho procesal del trabajo.

La acción de "amparo laboral" abre un insospechado campo para la acción de la justicia especializada a partir de la acción fiscalizadora de la Dirección del Trabajo (desde donde se presume, ha de provenir el mayor número de denuncias) y genera un arbitrio procesal adecuado (sin perjuicio que no cabe más que abogar por la supresión del formalismo que condiciona su ejercicio) para el control jurisdiccional de materias que hasta ahora carecían de tutela judicial efectiva y estaban radicadas sólo en la faz declarativa general de la interpretación administrativa. Permite anticipar a su vez, la instalación en los Tribunales del Trabajo de cuestiones tan relevantes y no menos complejas a la hora de la decisión del caso concreto, tales como el deber de no discriminación, el respeto a la libertad psíquica, la honra, la privacidad y otros derechos humanos fundamentales que pudieran verse afectados por las potestades de mando empresarial en el específico campo de las relaciones del trabajo.

Trabajo (el $1^{\circ}$ de septiembre de 2007), deberá asumir además las causas de "arrastre" no terminadas del sistema antiguo, combinando una increíble mixtura de procedimientos orales y escritos (los procedimientos de cobranza, debe recordarse, siguen siendo escritos).

Y así en Antofagasta, Rancagua, Punta Arenas y en las ciudades en que la reforma crea sólo un Juzgado de Letras del Trabajo.

${ }^{22}$ La distinción (que a primera vista pudiera extrañar) es común en la doctrina laboral y permite distinguir derechos propios que nacen de las relaciones individuales y colectivas del trabajo, tales como sindicación, huelga, a las prestaciones laborales legales y convenidas (específicos laborales), cubiertos por la acciones ordinarias, de aquellos que tiene cualquier persona natural con independencia de la calidad jurídica de trabajador y que aparecen reconocidos por la carta fundamental (inespecíficos o generales) protegidos por la acción especial que se introduce.

${ }^{23}$ Empero, se advierten en el diseño en tramitación importantes deficiencia, las que han sido planteadas al Senado por la Asociación Nacional de Magistrados en el instrumento antes citado: a) la inconveniencia de introducir una minuta previa a la contestación, b) inconvenientes relativos al orden de recepción de la prueba, c) la improcedencia de mantener la facultad judicial de reducir el número de absolventes, d) el límite legal de número de testigos, e) las escasas exigencias de fundamentación que tiene la sentencia dictada en la audiencia, f) la absoluta inexistencia de un sistema de cumplimiento de obligaciones de hacer, en razón de la total incompatibilidad de la obligación de hacer laboral clásica (la reincorporación al trabajo) con el tipo supletorio del procedimiento civil que se postula, ordenamiento común que no tiene normas para ejecutar una obligación de hacer de tal naturaleza y g) la posible inconstitucionalidad del límite legal de derechos protegidos en el procedimiento de tutela de derechos fundamentales. 
Se instala así, en los tribunales del trabajo, la justicia constitucional.

Con todo, al mismo tiempo, el procedimiento de tutela, plantea una interrogante sobre el impacto que tales nuevas competencias tendrán sobre el ingreso general de causas, en lo que se estima, parece ser una variable no considerada -ni siquiera estimativamente- al momento de definir el aumento de tribunales ${ }^{24}$.

La reforma ignora, por otra parte, la especialización de la segunda instancia (que se satisface sólo parcialmente con la existencia de salas especializadas), soslaya el tratamiento normativo necesario para lograr la capacitación y perfeccionamiento eficaz de los futuros jueces del trabajo (cuestiones estas últimas esenciales para incentivar la opción por la judicatura especial y remover las trabas institucionales que la presentan como un impedimento para hacer carrera judicial y como una estación de paso) y nada dice sobre el acceso a la justicia y el derecho a una defensa letrada con mínimos niveles de calidad.

¿No se acentuará acaso la desigualdad de armas en el marco de las nuevas destrezas que el juicio oral exige, si se deja buena parte de las defensas letradas a los alumnos en práctica de las Corporaciones de Asistencia Judicial, gravemente deficitarias en el sistema en boga?

Cabe advertir, finalmente, que las observaciones desde el plano teórico normativo son siempre parciales y habrá que esperar que la reforma nos muestre su última carta (ley de los procedimientos) para completar dicho análisis. A riesgo de caer en un lugar común en la apreciación de toda reforma procesal de la envergadura de la que se analiza, debe señalarse también, que ha de esperarse además, que la reforma dé sus primeros pasos para evaluar la capacidad del subsistema de justicia laboral de operar en el nuevo diseño normativo y determinar finalmente (en un dilema no siempre fácil de elucidar en sus justos alcances) si el legislador dio respuesta eficaz a las necesidades actuales de justicia del trabajo y si los jueces han podido estar la altura de las circunstancias.

\footnotetext{
24 Asimismo, la propia eficacia que el subsistema procesal laboral ofrece con la reforma -puede anticiparse- podría generar una mayor demanda por justicia del trabajo, elevando, como variable independiente adicional el número de causas. No debe desestimarse además cierta inadecuación de los intervinientes -en una primera época al menos- de cara a las destrezas necesarias que demanda la Reforma, que dilate más allá de lo esperado los procedimientos y provoque una recarga del sistema ya desde sus inicios (Una reciente simulación de juicio oral llevada a efecto ante la Comisión de Trabajo del H. Senado, en un juicio rutinario de despido injustificado, se extendió -sin sentenciapor casi dos horas).
} 